\title{
Plastocrono e rendimento de feijão-de-vagem cultivado sob ambiente protegido e no ambi- ente externo em semeadura tardia no outono
}

\author{
Plastochron and snap bean yield grown under protected environment and in open field in late fall \\ sowing
}

\author{
Arno Bernardo Heldwein ${ }^{\mathrm{I}}$ Nereu Augusto Streck ${ }^{\mathrm{I}^{*}}$ Vinícius Soares Sturza $^{\mathrm{II}}$ \\ Luis Henrique Loose ${ }^{\mathrm{II}}$ Alencar Junior Zanon ${ }^{\mathrm{II}}$ Marcos Toebe ${ }^{\mathrm{II}}$ André Trevisan de Souza ${ }^{\mathrm{II}}$ \\ Marcelo Boschmann Peters ${ }^{\text {II }}$ Fábio Karlec ${ }^{\text {II }}$
}

\section{RESUMO}

O feijão-de-vagem (Phaseolus vulgaris L.), ou feijão-vagem, é uma hortaliça que, durante o outono no Estado do Rio Grande do Sul, pode ser favorecida pelo cultivo no interior de estufa plástica (cultivo protegido). A determinação do intervalo de tempo entre a emissão de dois nós consecutivos em dicotiledôneas, denominada plastocrono, é importante em estudos de modelagem e para o manejo dessa hortaliça. O objetivo deste estudo foi determinar o plastocrono e o rendimento da cultura de feijão-de-vagem em cultivo sob ambiente protegido por estufa plástica e no ambiente externo. Um experimento foi conduzido durante o outono de 2009, em Santa Maria, em dois ambientes: em ambiente protegido (estufa plástica de polietileno de baixa densidade, com $100 \mu \mathrm{m}$ de espessura) e em ambiente externo (céu aberto). Foram determinadas a densidade de fluxo de radiação solar global incidente, a temperatura do ar, a soma térmica diária, a emissão de nós (plastocrono) na haste principal até o florescimento e o rendimento precoce de vagens nos dois ambientes. A disponibilidade de radiação foi $26 \%$ menor no ambiente protegido, e as temperaturas mínima, média e máxima diária foram superiores. O plastocrono foi maior (velocidade de emissão de nós foi menor) no ambiente protegido, enquanto o rendimento de vagens foi similar nos dois ambientes. A redução da densidade de fluxo de radiação solar global incidente em função da cobertura plástica foi apontada como a causa da menor velocidade de emissão de nós (maior plastocrono) pelas plantas no ambiente protegido, enquanto o crescimento reprodutivo no ambiente protegido foi similar ao do ambiente externo, provavelmente devido a menor exposição das plantas a possíveis estresses, mecânico por vento e hídrico parcial nas horas mais quentes dos dias de maior demanda hídrica, além do aumento da fração difusa da radiação solar, que, em parte, compensou o sombreamento pela estufa.

Palavras-chave: emissão de nós, estufa plástica, radiação global, Phaseolus vulgaris.

\section{ABSTRACT}

Snap bean (Phaseolus vulgaris L.) is a horticultural crop that is enhanced during Fall in Rio Grande do Sul State, which can be favored by growing inside a plastic greenhouse (protected cropping). The estimation of the time interval between the appearance of two successive nodes on a dicot stem, known as plastochron, is important in modeling studies and for crop management. The objective of this study was to evaluate the plastochron and the yield of snap bean grown inside plastic greenhouse (protected environment) and in the open field. An experiment was carried out in Santa Maria, RS, Brazil, during the Fall 2009 in two environments: protected environment (plastic house covered with $100 \mu \mathrm{m}$ of thickness low density polyethylene) and in the open field. Solar radiation, air temperature, thermal time, the main stem node appearance (plastochron) and pod yield were determined. Solar radiation was, 26\% lower in the protected environment, and minimum, mean and maximum air temperatures were greater in the protected environment. The plastochron was higher (lower node appearance rate) in the protected environment whereas pod yield was similar in the two environments. The reduction in solar irradiation, caused by the plastic cover, was pointed out as a major cause for the lower node appearance rate (greater plastochron) of the plants in the protected environment whereas reproductive growth in the protected environment was similar to the one in the open field most likely because of the increase in the diffuse fraction of solar radiation that partially compensated the plastic shading, and because of the less plants exposure to possible mechanic stresses as wind and hydraulic during the hottest hours of the day when water demand is the highest.

Key words: node appearance, plastic greenhouse, solar radiation, Phaseolus vulgaris.

IDepartamento de Fitotecnia, Centro de Ciências Rurais (CCR), Universidade Federal de Santa Maria (UFSM), 97105-900, Santa Maria, RS, Brasil. E-mail: nstreck2@yahoo.com.br. *Autor para correspondência.

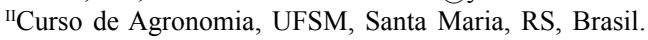




\section{INTRODUÇÃO}

O feijão-de-vagem, também conhecido como feijão-vagem, pertence à mesma família e espécie botânica do feijão comum (Phaseolus vulgaris L.) e é uma hortaliça da qual são consumidas as vagens imaturas (FILGUEIRA, 2000). Essa hortaliça é favorecida por temperaturas do ar na faixa de 18 a $30^{\circ} \mathrm{C}$ durante seu ciclo de desenvolvimento, não tolerando temperaturas elevadas, nem geadas (PRELA \& RIBEIRO, 2002). Em função dessas exigências bioclimáticas, em regiões subtropicais, como no Rio Grande do Sul (RS), a cultura do feijão-de-vagem é cultivada a céu aberto (ambiente externo), em duas épocas, na primavera e no outono. No entanto, durante o outono do RS, a baixa radiação solar, a baixa temperatura do ar (inclusive com geadas) e o excesso de chuvas são limitantes para a produção de feijão-devagem no ambiente externo (perdas qualitativas e quantitativas), especialmente a partir de maio, época em que o preço da vagem na etapa de comercialização é maior (FELTRIM et al., 2006). Parte dessas limitações ambientais no $\mathrm{RS}$ podem ser minimizadas com o cultivo do feijão-de-vagem no interior de estufas plásticas (cultivo protegido), em que a temperatura do ar é maior e há a proteção contra chuva, reduzindo o molhamento foliar e desfavorecendo o estabelecimento de doenças foliares. Assim, o feijão-de-vagem é uma cultura importante em sistemas de cultivo protegido no RS por agregar renda ao agricultor, em semeadura antecipada ou atrasada nesses ambientes na época de primavera e de outono, respectivamente, e por ser um componente da lista de culturas em rotação ao tomateiro, principal cultura em estufas plásticas no RS (BURIOL et al., 2000), mas que, em cultivo no solo, tem aumento de vários problemas relacionados a doenças e pragas.

$\mathrm{O}$ uso de coberturas plásticas feitas com polietileno de baixa densidade (PEBD), nas regiões subtropicais, possibilita o crescimento e desenvolvimento das culturas nas épocas em que os elementos meteorológicos no ambiente externo são limitantes, em função de alterações nos balanços de radiação e de energia. A radiação solar global é um importante elemento meteorológico no manejo de cultivos protegidos, pois alterações de temperatura, umidade relativa do ar e concentração interna de gás carbônico estão a ela relacionadas (STRECK et al., 2002). A determinação das alterações ocasionadas pela cobertura plástica nos elementos metereológicos e nos parâmetros de crescimento e desenvolvimento é importante para o aperfeiçoamento do manejo das culturas cultivadas no interior desses ambientes.
$\mathrm{O}$ número de nós $(\mathrm{NN})$ em uma haste é utilizado como parâmetro de desenvolvimento vegetativo em diferentes espécies, pois está relacionado com o surgimento de outros órgãos de plantas, como folhas e inflorescências (BAKER \& REDDY, 2001; STRECK et al., 2008b). Para sua determinação, é frequente a utilização do conceito de plastocrono, que é definido, em dicotiledôneas, como o intervalo de tempo entre o aparecimento de dois nós sucessivos na haste, com dimensão de tempo.nó ${ }^{-1}$ (STRECK et al., 2005). Utilizando-se a soma térmica como medida de tempo, a qual é definida como a soma diária dos valores de temperatura média diária acima de uma temperatura base (Tb), o plastocrono é a soma térmica necessária para o aparecimento de um novo nó na haste da planta, com unidade em ${ }^{\circ} \mathrm{C}$ dia nó ${ }^{-1}$ (STRECK et al., 2008b). A determinação e a comparação do plastocrono em feijãode-vagem cultivado no ambiente protegido por estufa plástica e no ambiente externo é importante, tanto em estudos básicos que envolvem modelagem do desenvolvimento, quanto em estudos aplicados para melhorar o manejo dessa hortaliça, a fim de aumentar o rendimento, especialmente dentro de estufa que tem uma área limitada para o cultivo. No entanto, a literatura carece dessas informações, motivando a realização deste trabalho.

O objetivo deste estudo foi determinar o plastocrono e o rendimento da cultura do feijão-devagem em cultivo tardio, no outono, sob ambiente protegido por estufa plástica e no ambiente externo.

\section{MATERIAL E MÉTODOS}

O experimento foi conduzido em ambiente protegido e em ambiente externo, na área experimental do Departamento de Fitotecnia da Universidade Federal de Santa Maria (latitude 29॰42’23'S, longitude $53^{\circ} 43^{\prime} 15^{\prime}$ 'W e altitude de $95 \mathrm{~m}$ ), no período de 23/03/ 2009 a 25/06/2009.

O clima do local, segundo a classificação de Köppen, é do tipo Cfa, subtropical úmido com verões quentes e sem estação seca definida. O solo do local é uma transição entre a Unidade de Mapeamento São Pedro (Argissolo Vermelho distrófico arênico) e a Unidade de Mapeamento Santa Maria (Alissolo Hipocrômico argilúvico típico) (STRECK et al., 2008a).

$\mathrm{O}$ experimento em ambiente protegido foi realizado dentro de uma estufa plástica com $18 \mathrm{~m}$ de comprimento (direção norte-sul), 10m de largura e altura de $3 \mathrm{~m}$ na parte central e $2 \mathrm{~m}$ de pé direito, coberta com PEBD de $100 \mu \mathrm{m}$ de espessura. O manejo das cortinas laterais e portas frontais visando à ventilação e renovação do ar foi realizado manualmente, sendo 
abertas as cortinas laterais até $2 \mathrm{~m}$ de altura do solo e as portas de manhã (entre 8 e 10h) e fechando-as à tarde (entre 16 e 18h), conforme as condições meteorológicas do dia (nos dias quentes e ensolarados a abertura era mais cedo e o fechamento mais tarde, nos dias frios e ensolarados a abertura era mais tarde e o fechamento mais cedo, e nos dias nublados e chuvosos a estufa era mantida fechada). Aárea de ambiente externo estava situada a $5 \mathrm{~m}$, ao lado oeste da estufa, e possuía $18 \mathrm{~m}$ de comprimento e $5 \mathrm{~m}$ de largura.

Foi realizado o preparo convencional do solo nos dois ambientes com o auxílio de um microtrator, seguido de adubação de acordo com a recomendação para a cultura. Foram realizados a demarcação e o alinhamento de camalhões com aproximadamente $0,20 \mathrm{~m}$ de altura e $0,40 \mathrm{~m}$ de largura, distanciados entre si em $0,8 \mathrm{~m}$. Os camalhões foram cobertos com mulching de filme opaco de PEBD de cor preta $30 \mu \mathrm{m}$ de espessura, enterrando-se suas bordas laterais a uma profundidade de $0,10 \mathrm{~m}$ abaixo da base do camalhão.

A cultivar usada foi a 'Macarrão', de crescimento indeterminado. A semeadura ocorreu em 23/03/2009, com espaçamento entre plantas de $0,20 \mathrm{~m} \mathrm{e}$ entre filas de $1,00 \mathrm{~m}$. Foram semeadas duas sementes por cova e, após a emergência das plantas, fez-se o raleio, deixando-se uma planta por cova. Durante o período de crescimento das plantas, foi feito o desbrote das brotações axilares das plantas, deixando-se apenas a haste principal, que foi conduzida verticalmente com fio de ráfia. A irrigação foi realizada por tubo gotejadores sob o mulching. O sistema de irrigação dentro da estufa era independente do sistema localizado fora da estufa. Exceto nos dias nublados e chuvosos, quando a estufa era mantida fechada, nos demais dias, a irrigação foi realizada diariamente pela manhã, com turno de irrigação de 10 minutos. Com esse manejo da irrigação, as plantas puderam crescer e se desenvolver sem deficiência hídrica aparente nas folhas, nos dois ambientes. O controle de pragas e doenças foi realizado de forma preventiva, com a aplicação semanal de lambda-cialotrina e metiram+piraclostrobina, respectivamente.

O delineamento experimental foi $\mathrm{o}$ inteiramente casualizado. Os tratamentos foram os dois ambientes de cultivo (ambiente protegido e ambiente externo). A emergência das plântulas foi determinada quando $50 \%$ destas estavam emergidas em cada ambiente. Uma semana após a emergência, foram identificadas 16 plantas, com arames coloridos, em cada ambiente, e cada planta foi considerada uma repetição, em cada ambiente, totalizando 32 plantas.

Nas plantas marcadas, contou-se o número de nós visíveis na haste principal três vezes por semana (terça, quinta e sábado) até o florescimento, considerado como o momento em que $50 \%$ dessas plantas apresentaram pleno florescimento. Um nó foi considerado visível quando a folha associada a ele tinha as bordas de pelo menos um limbo foliar desenrolado, não mais se tocando (JOHNSON, 1997).

Dados horários de densidade de fluxo de radiação solar global e temperatura do ar no ambiente externo, durante o período experimental, foram registrados na Estação Climatológica Principal do 8o Distrito de Meteorologia do Instituto Nacional de Meteorologia, localizada aproximadamente a $100 \mathrm{~m}$ da área experimental, e no interior da estufa esses dados foram coletados por uma estação automática, instalada no centro da estufa.

A soma térmica diária $\left(\mathrm{STd},{ }^{\circ} \mathrm{C}\right.$ dia) nos dois ambientes foi calculada por (ARNOLD,1960): $\mathrm{STd}=(\mathrm{Tm}$ - Tb) . 1dia, em que: Tmé a temperatura média diária do ar, calculada pela média aritmética das temperaturas horárias, e Tb é a temperatura base para o feijão-devagem, definida como a temperatura mínima abaixo da qual não há emissão de nós. Assumiu-se a $\mathrm{Tb}=10^{\circ} \mathrm{C}$ (KISH \& OGLE, 1980). A soma térmica acumulada (STa, ${ }^{\circ} \mathrm{C}$ dia) foi calculada somando-se as STd, ou seja, $\mathrm{STa}=\Sigma \mathrm{STd}$.

Para cada planta, estimou-se a regressão linear entre o NN na haste principal e a STa a partir da emergência (STRECK et al., 2005). Na regressão linear, utilizou-se o $\mathrm{NN}$ até 15 nós. O plastocrono $\left({ }^{\circ} \mathrm{C}\right.$ dia nó $\left.{ }^{-1}\right)$ foi calculado como o inverso do coeficiente angular da regressão linear entre NN e STa (BAKER \& REDDY, 2001).

A fim de comparar as alterações provocadas pela cobertura de PEBD, foram calculados os seguintes índices pela razão entre os valores das variáveis obtidas no ambiente protegido e os valores no ambiente externo: $\mathrm{I}_{\mathrm{Rg}}=\mathrm{Rg}_{\mathrm{ap}} / \mathrm{Rg}_{\mathrm{ae}}$, em que $\mathrm{I}_{\mathrm{Rg}}$ é o índice de radiação global, $\mathrm{Rg}_{\mathrm{ap}}$ é a radiação solar global incidente sobre o cultivo no ambiente protegido ( $\left.\mathrm{MJ} \mathrm{m}^{-2} \mathrm{dia}^{-1}\right)$ e $\mathrm{Rg}_{\mathrm{ae}}$ é a radiação solar global incidente sobre o cultivo no ambiente externo $\left(\mathrm{MJ} \mathrm{m}^{-2} \mathrm{dia}^{-1}\right)$. $\mathrm{I}_{\text {ST DIÁRIA }}=\mathrm{ST}$

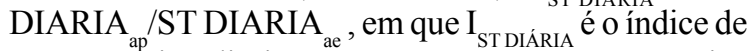
soma térmica diária, ST DIARIA é a soma térmica diária no ambiente protegido $\left({ }^{\circ} \mathrm{C}\right.$ dia $)$ e ST DIARIA $a$ é a soma térmica diária no ambiente externo $\left({ }^{\circ} \mathrm{C} \mathrm{dia}\right)$. $\mathrm{I}_{\text {PLASTOCRONO }}=$ PLASTOCRONO $_{\text {ap }} /$ PLASTOCRONO $_{\text {ae }}$, em que I ILASTOCRONo é o índice de plastocrono, PLASTOCRONO $_{\mathrm{ap}}$ é o plastocrono no ambiente em cultivo protegido $\left({ }^{\circ} \mathrm{C}\right.$ dia nó $\left.{ }^{-1}\right)$ e PLASTOCRONO ${ }_{a e}$ é o plastocrono no cultivo em ambiente externo $\left({ }^{\circ} \mathrm{C}\right.$ dia nó $\left.{ }^{-1}\right)$. $\mathrm{I}_{\text {RENDIMENTO }}=$ RENDIMENTO $_{\text {ap }} /$ RENDIMENTO $_{\text {ae }}$, em que $\mathrm{I}_{\text {RENDIMENTO }}$ é o índice de rendimento, RENDIMENTO $\mathrm{O}_{\text {ap }}$ é o rendimento no ambiente protegido $\left(\mathrm{t} \mathrm{ha}^{-1}\right) \mathrm{e}$ RENDIMENTO $_{\mathrm{ae}}$ é o rendimento no cultivo em ambiente externo $\left(\mathrm{t} \mathrm{ha}^{-1}\right)$. 
A colheita foi realizada em 23/05/2009, 05/ 06/2009 e 19/06/2009. O ponto de colheita foi considerado quando mais de $50 \%$ das plantas apresentavam vagens com máximo crescimento, mas ainda não fibrosas. O cálculo do rendimento de vagens foi realizado somando-se o peso total de vagens frescas colhidas nas plantas marcadas nas três datas de colheita, para cada ambiente. Os valores de densidade de fluxo de radiação solar global média diária incidente $\left(\mathrm{MJ} \mathrm{m}^{-2} \mathrm{dia}^{-1}\right)$, de soma térmica média diária $\left({ }^{\circ} \mathrm{C} \mathrm{dia}\right)$, de plastocrono $\left({ }^{\circ} \mathrm{C}\right.$ dia nó $\left.{ }^{-1}\right)$ e de rendimento $\left(\mathrm{t} \mathrm{ha}^{-1}\right)$ no ambiente protegido e no ambiente externo foram comparados estatisticamente pelo teste $t$, a $5 \%$ de significância.

\section{RESULTADOS E DISCUSSÃO}

Os valores acumulados de densidade de fluxo de radiação solar global incidente durante o período experimental (emergência até a semana posterior à última colheita) foram de $794,81 \mathrm{MJ} \mathrm{m}^{-2} \mathrm{e}$ $1076,65 \mathrm{MJ} \mathrm{m}^{-2}$, para os ambientes protegido e externo, respectivamente. Os valores diários de densidade de fluxo de radiação solar global incidente variaram de $0,275 \mathrm{MJ} \mathrm{m}^{-2} \mathrm{dia}^{-1}$ até $17,171 \mathrm{MJ} \mathrm{m}^{-2} \mathrm{dia}^{-1}$ no interior da estufa e $1,087 \mathrm{MJ} \mathrm{m}^{-2}$ dia $^{-1}$ até $21,124 \mathrm{MJ} \mathrm{m}^{-2} \mathrm{dia}^{-1}$ no ambiente externo, diferindo estatisticamente entre si (Figura 1A e 1D). O índice $\mathrm{I}_{\mathrm{Rg}}$, que indica a transmissividade média do PEBD, foi de $74 \%$. Essa transmissividade da cobertura de polietileno está dentro da faixa de transmissividade relatada em outros estudos, como, por exemplo, em BURIOL et al. (1995), que, em trabalho realizado também em Santa Maria, RS, em estufa com cobertura de PEBD com $100 \mu \mathrm{m}$ de espessura, relatam uma variação diária da transmissividade da cobertura plástica ao longo do dia de 56,2 a $81,3 \%$ para as primeiras horas do dia e para as horas próximas ao meio-dia, respectivamente. $\mathrm{O}$ valor é superior ao encontrado por SOUZA \& ESCOBEDO (1997), também em cultivo de feijão-vagem durante a primavera $(65 \%)$, e inferior ao valor relatado em FRISINA \& SCOBEDO (1999), em cultivo de alface $(79,6 \%)$, sendo ambos os estudos realizados em Botucatu, São Paulo (SP).

A temperatura máxima diária do ar ultrapassou $32^{\circ} \mathrm{C}$, acima da qual ocorrem prejuízos à cultura, como abscisão de botões florais, flores e vagens jovens $(<3 \mathrm{~cm})$ (KONSENS et al., 1991), em oito dias no ambiente protegido (Figura 1B) e em três dias no ambiente externo (Figura 1C), mas esses dias foram registrados antes dos estágios de início da floração e início de formação de vagens, que são os estágios mais afetados à incidência de temperaturas elevadas, em duas cultivares de feijoeiro comum (DIDONET \& VITÓRIA,
2006), indicando que as temperaturas máximas não foram limitantes para a cultura nos dois ambientes.

Os menores valores de temperatura média diária do ar, nos dois ambientes (protegido e externo), foram de 9,3 e $7,1^{\circ} \mathrm{C}$, e os números totais de dias com temperatura média abaixo da $\mathrm{Tb}\left(10^{\circ} \mathrm{C}\right)$ foram dois no ambiente protegido (Figura 1B) e 11 no ambiente externo (Figura 1C). Como resultado da maior temperatura média diária no interior da estufa, a soma térmica média diária no cultivo protegido foi, de acordo com o I $18 \%$ superior em relação ao ambiente externo (Figura 1D). A temperatura mínima diária do ar foi também maior no ambiente protegido (Figura 1B e 1C), indicando os efeitos benéficos do efeito estufa do PEBD, que, embora tenha alta transmissividade à radiação de onda longa (baixo efeito estufa), na condição de campo, ocorre condensação do vapor de água na superfície interna do plástico durante a noite e assim o conjunto plástico + filme de água condensado tem um efeito estufa que beneficia os cultivos (BURIOL et al., 1995).

A regressão linear entre NN e STa teve coeficiente de determinação de 0,98 para ambos os ambientes, indicando que a emissão de nós em feijãode-vagem é fortemente dependente da temperatura do ar, como foi relatado para outras espécies, como a soja (STRECK et al., 2008) e no meloeiro (STRECK et al., 2005), e que a estimativa do plastocrono pelo método da regressão linear entre o NN e STa é uma metodologia apropriada. O plastocrono foi maior no cultivo em ambiente protegido $\left(23,9^{\circ} \mathrm{C}\right.$ dia nó $\left.{ }^{-1}\right)$ do que no cultivo em ambiente externo $\left(21,6^{\circ} \mathrm{C}\right.$ dia nó $\left.{ }^{-1}\right)$ (Figura 1D), indicando que a taxa ou velocidade de aparecimento de nós, em base de ${ }^{\circ} \mathrm{C}$ dia, é menor no interior da estufa. No entanto, como a STd no interior da estufa é maior que no ambiente externo, o $\mathrm{NN}$ durante o período experimental foi similar nas datas de amostragem, chegando a 15 nós no mesmo dia após a emergência (38DAE), compensando o maior plastocrono na estufa. $\mathrm{O}$ maior plastocrono (menor desenvolvimento vegetativo) no ambiente protegido pode ser explicado pela menor disponibilidade de radiação solar dentro da estufa.

Não houve diferença de rendimento de vagem entre os dois ambientes (Figura 1D), sendo a média dos dois ambientes de $23,7 \mathrm{t} \mathrm{ha}^{-1}$, valor que está dentro da faixa de rendimento de aproximadamente 22 e $37 \mathrm{t} \mathrm{ha}^{-1}$ obtida por ARAUJO et al. (2001) e de 13 a $25 \mathrm{t}$ ha $^{-1}$ obtida por OLIVEIRA et al.(2007). Esses resultados indicam que, apesar da menor disponibilidade de radiação solar no interior da estufa, o crescimento reprodutivo das plantas de feijão-de-vagem foi similar nos dois ambientes, sugerindo que as plantas utilizam melhor a radiação no ambiente protegido pela estufa do que no ambiente externo. A hipótese mais provável 


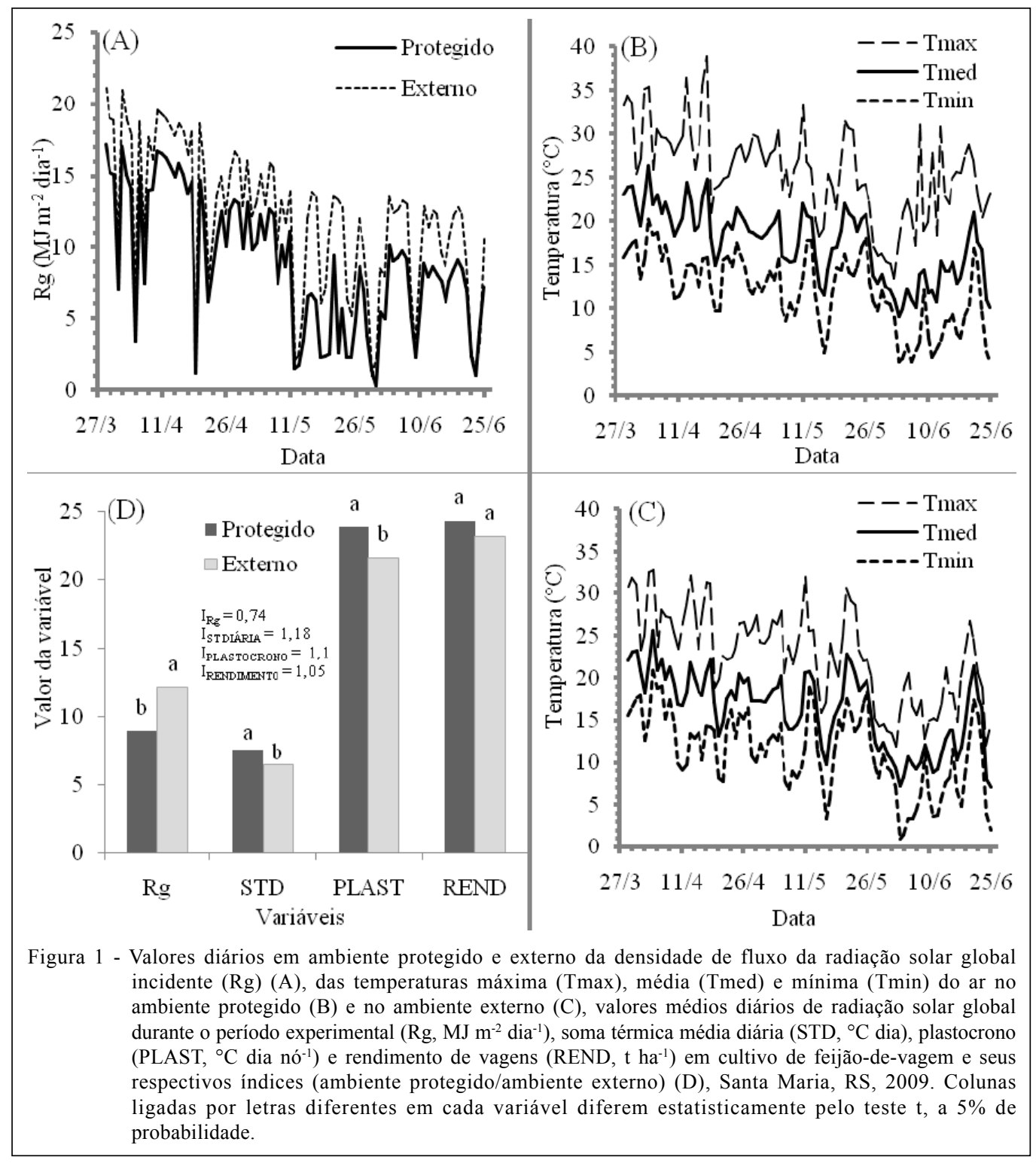

para a melhor eficácia do uso da radiação solar na estufa é a maior disponibilidade de radiação solar difusa nesse ambiente proporcionado pelo poder difusor do PEBD (BURIOL et al., 1995), a qual é mais eficiente em penetrar no interior do dossel vegetal que a componente direta da radiação solar, que predomina no ambiente externo, compensando assim essa menor disponibilidade de radiação direta. No período de outono, em diferentes locais do Estado do RS, verifica-se a ocorrência de valores médios de radiação solar global inferiores ao valor de limite trófico (mínimo de energia necessário para produção de fotoassimiliados necessários para a manutenção da planta) de $8,4 \mathrm{MJ} \mathrm{m}^{-2}$ dia $^{-1}$ para as hortaliças de verão (FAO, 1990; ANDRIOLO, 2000; BURIOL et al., 2000). Durante o período experimental deste estudo, no ambiente externo, ocorreram 19 dias com valores de $\mathrm{Rg}$ inferiores a $8,4 \mathrm{MJ} \mathrm{m}^{-2} \mathrm{dia}^{-1}$, enquanto no ambiente protegido esse número foi 38 dias, ou seja, o dobro, corroborando a hipótese da compensação da menor disponibilidade de radiação solar global pela maior fração difusa no interior da estufa, no crescimento das plantas de feijão-de-vagem.

\section{CONCLUSÃO}

O uso de cobertura plástica para cultivo de feijão-de-vagem no outono leva ao aumento no plastocrono, no interior desse ambiente, em razão da maior temperatura em relação ao ambiente externo, mas sem efeito no rendimento de vagens dessa hortaliça. 


\section{REFERÊNCIAS}

ANDRIOLO, J.L. Fisiologia da produção de hortaliças em ambiente protegido. Horticultura Brasileira, Brasília, v.18, supl, p.26-33, 2000.

ARAÚJO, J.S. et al. Rendimento do feijão-vagem cultivado com esterco suíno e adubação mineral. Revista Ceres, v.48, n.278, p.501-510, 2001. Disponível em: <www.ceres.ufv.br/ CERES/revistas/V48N278P10601.pdf>. Acesso em: $03 \mathrm{dez}$. 2009 .

ARNOLD, C.Y. Maximum-minimum temperatures as a basis for computing heat units. Proceedings of the American Society for Horticultural Sciences, Boston, v.76, p.682692, 1960 .

BAKER, J.T.; REDDY, V.R. Temperature effects on phenological development and yield of muskmelon. Annals of Botany, Oxford, v.87, p.605-613, 2001. Disponível em: $<$ http://aob.oxfordjournals.org/cgi/reprint/87/5/605.pdf $>$. Acesso em: 30 set. 2009. doi: 10.1006/anbo.2001.1381.

BURIOL, G.A. et al. Transmissividade à radiação solar do polietileno de baixa densidade utilizado em estufas. Ciência Rural, Santa Maria, v.25, n.1, p.1-4, 1995.

BURIOL, G.A. et al. Disponibilidade de radiação solar nos meses mais frios do ano para o cultivo do tomateiro no estado do Rio Grande do Sul. Pesquisa Agropecuária Gaúcha, Porto Alegre, v.6, n.1, p.18-22, 2000

COKSHULL, K.E. et al. The influence of shading on yield of glasshouse tomatoes. Journal of Horticultural Science, Ashford, v.67, p.11-24, 1992.

DIDONET, A.D.; VITÓRIA, T.B. Resposta do feijoeiro comum ao estresse térmico aplicado em diferentes estágios fenológicos. Pesquisa Agropecuária Tropical, v.36, n.3, p.199-204, 2006.

FAO. Protected cultivation in the Mediterranean climate. Rome, 1990. 313p. (FAO Plant Production and Protection Paper, 101).

FELTRIM, A.L. et al. Produção de chicória em função do período de cobertura com tecido de polipropileno. Horticultura Brasileira, Brasília, v.24, n.2, p.249-254, 2006. Disponível em: $<$ http://www.scielo.br/scielo.php?script=sci_arttext\&pid=S0102$05362006000200027 \& \operatorname{lng}=$ pt\&nrm=iso $>$. Acesso em: 24 ago. 2009. doi: 10.1590/S0102-05362006000200027.

FILGUEIRA, F.A.R. Novo manual de olericultura: agrotecnologia moderna na produção de hortaliças. Viçosa: UFV, 2000. 421p.
FRISINA, V. de A.; ESCOBEDO, J.F. Balanço de radiação e energia da cultura de alface em estufa de polietileno. Pesquisa Agropecuária Brasileira, Brasília, v.34, n.10, p.1775-1786, 1999. Disponível em: <http://www.scielo.br/pdf/pab/v34n10/ 7177.pdf>. Acesso em: 7 set. 2009. doi: 10.1590/S0100204X1999001000003.

JOHNSON, S.R. How a soybean plant develops. Ames: Iowa Stale University of Science and Technology, and Cooperative Extension Service, 1997. 18p. (Special Report n.53).

KISH, A.J.; OGLE, W.L. Improving the heat unit system in predicting maturity date of snap beans. Hortscience, Virginia, v. 15, n.2, p.140-141, 1980

KONSENS, I. et al. The effect of temperature on the production and abscission of flowers and pods in snap bean (Phaseolus vulgaris L.). Annals of Botany, London, v.67, n.5, p.391399, 1991 .

OLIVEIRA, A.P. et al. Rendimento de feijão-vagem em função de doses de K2O. Horticultura Brasileira, v.25, n.1, p.2933, 2007. Disponível em: <http://www.scielo.br/pdf/hb/v25n1/ a07v25n1.pdf >. Acesso em: 03 dez. 2009. doi: 10.1590/ S0102-05362007000100007.

PRELA, A.; RIBEIRO, A.M.A. Determinação de graus-dia acumulados e sua aplicação no planejamento do cultivo de feijãovagem (Phaseolus vulgaris L.) para Londrina-PR. Revista Brasileira de Agrometeorologia, Santa Maria, v.10, n.1, p.83-86, 2002.

SOUZA, J.L.; ESCOBEDO, J.F. Balanço de radiação em cultivos de feijão-vagem com e sem cobertura de polietileno. Pesquisa Agropecuária Brasileira, Brasília, v.32, n.1, p.1-15, 1997.

STRECK, L. et al. Tecnologia para diminuir temperaturas elevadas no interior de estufas plásticas. Revista Brasileira de Agrometeorologia, Santa Maria, v.10, n.2, p.207-214, 2002 .

STRECK, N.A. et al. Estimativa do plastocrono em meloeiro (Cucumis melo L.) cultivado em estufa plástica em diferentes épocas do ano. Ciência Rural, Santa Maria, v.35, n.6, p.1275-1280, 2005. Disponível em: $<$ http://www.scielo.br/scielo.php?pid=S0103$84782005000600008 \&$ script $=\mathrm{sci}$ abstract\&tlng $=\mathrm{e}>$. Acesso em: 24 ago. 2009. doi: 10.1590/S0103-84782005000600008.

STRECK, E.V. et al. Solos do Rio Grande do Sul. 2.ed. Porto Alegre: Emater/RS-ASCAR, 2008a. 222p.

STRECK, N.A. et al. Estimativa do plastocrono em cultivares de soja. Bragantia, São Paulo, v.67, p.67-73, 2008b. Disponível em: <http://www.scielo.br/scielo.php?pid=S0006$87052008000100008 \&$ script $=$ sci arttext $>$. Acesso em: 24 ago. 2009. doi: 10.1590/S0006-87052008000100008. 